\title{
The Causal Relationship Model of Advocacy of the Business Administration Program in General Management Phranakhon Rajabhat University
}

\author{
Phairoj Butchiwan', Chanthana Udom², Nongnooch Paiboonrattananon ${ }^{3}$, Phrapalad Somchai \\ Damnoen $^{4}$, Harin Sachdev 5 \\ 1,2,3 Pranakhon Rajabhat University, ${ }^{4}$ Mahachulalongkornrajavidyalaya University, ${ }^{5}$ Mahidol University \\ ${ }^{1}$ phairoj@pnru.ac.th, ${ }^{2}$ chanpnru@gmail.com, ${ }^{3}$ chanthana_u@hotmail.com, ${ }^{4}$ somchai.dam@mcu.ac.th, ${ }^{5}$ harin_9@yahoo.com
}

\begin{abstract}
This study aims (1) to create the causal relationship model of advocacy of the Business Administration Program in General Management, Phranakhon Rajabhat University. (2) to examine the concordance between the causal relationship model of advocacy of the Business Administration Program in General Management and empirical data. The sample group was 403 students in General Management from the simple random sampling method. The instrumental for data collection was an online questionnaire with p 7 -value 0.986 . Statistics used in this research are percentage, mean, skewness, kurtosis, analysis of Pearson's correlation coefficient, and factor analysis and path analysis. This is to investigate the causal relationship model by Structural Equation Modeling by using software for social science. The results indicated that the causal relationship model of advocacy of the Business Administration Program in General Management consisted of 5 factors that influenced advocacy: expectation, instructor, welfare and services, live and learn, and advocacy.
\end{abstract}

Keywords

Advocacy, the Business Administration Program, Internal branding

Article Received: 10 August 2020, Revised: 25 October 2020, Accepted: 18 November 2020

\section{Introduction}

General Management is a program in the Business Administration of Faculty of Management Sciences, Phranakhon Rajabaht University, with the highest number of regular students in the Faculty of Management Sciences (Office of Academic Phranakhon Rajabhat University, 2019). General Management is fully aware of the missions of the University, including the administration of efficient governmental performances to drive our strategies for the development of local community and integration of effective learning experiences.

Management of Curriculum in General Management Program is committed to developing innovative curriculum administration to achieve standards and quality assurances of higher education. We, thus, realize the benefits of building a relationship with students in a long term. This will enable the General Management Department to receive corporation and participation from students, which expectedly results in curriculum administration that is consistent with learning behaviours and lifestyles of students nowadays. Besides, building a relationship is considered to be a significant mechanism of creating a bond and a good experience for students to properly recognize and understand the curriculum as well. The acknowledgement will also allow students to be representatives of the program to willingly distribute and share their learning experiences for further understandings of surrounding people.

The review of the literature related to "Advocacy" was thoroughly conducted in this study (Isaraphakdee, 2018). It is found that the particular concept could be applied to the form of "Program Advocacy", which is considered to be the other innovative curriculum administration. The approach is to combine brand supporting behaviour concept (Thongdaeng, et. al., 2018) and costumer's behaviour concept (Samittikrai, 2018) through several contact points
(Isaraphakdee, 2018; Wichitchamaree, 2016), the expectation that must provide confidence for learners (Office of the Higher Education Commission, 2018), the live and learn (Thipboonsub \& Rojsongkram, 2018), welfare and services (Krainatee, Muhamad \& Nakudom, 2017), and instructors (Rimpadee, Mookda, Prapakiet \& Supakitkosol, 2015). These will enable students to become program advocates, with well understanding and relationships. Accordingly, this will be beneficial for learning experiences and academic services in the responsible area of the university to pushing for effective cooperation among stakeholders.

According to those concepts, students in General Management will be the key performers as the program advocates. This would allow the management of curriculum to achieve the ultimate goal of being part of lifestyles, creating learning experiences, and building long term relationships with stakeholders during the course (new students, parents, employers, and the local community in an academic area, etc.). Generally, the implementation of Program Advocacy in the innovative program will not only enable students to be advocators but also spokespeople (Isaraphakdee, 2018), who has a well understanding of the course in all aspects. Thus, they would be qualified to talk, express, and support the responsible community in various ways.

Therefore, the study of the Causal Relationship Model of Advocacy of the Business Administration Program in General Management will be the guidance to realize factors and influences of each factor on the causal relationship of advocacy of the Business Administration Program in General Management. This would advance knowledge and innovative program administration. Moreover, it can be utilized as a tool to develop the General Management Program, Faculty of Management Sciences, and Phranakhon Rajabhat University, to be adaptable to the current situation. 


\section{Objectives}

1. To build the Causal Relationship Model of Advocacy of the Business Administration Program in General Management, Phranakhon Rajabhat University

2. To investigate the concordance between the Causal Relationship Model of Advocacy of the Business Administration Program in General Management with the empirical data

\section{Research Scope}

The content is the study of factors of expectation, live and learn, welfare and services, instructor, and advocacy.

The group of population in this study is students in the General Management Program of Faculty of Management Sciences, Phranakhon Rajabhat University.

The field data collection is located at Phranakhon Rajabhat University, in December 2019 - January 2020.

\section{Conceptual Framework}

The researchers developed the framework from the relevant concepts and studies. We comprehensively reviewed various literature to define the path analysis, as well as indicate latent and observed variables. The conceptual framework of the research is thus summarized as follows:

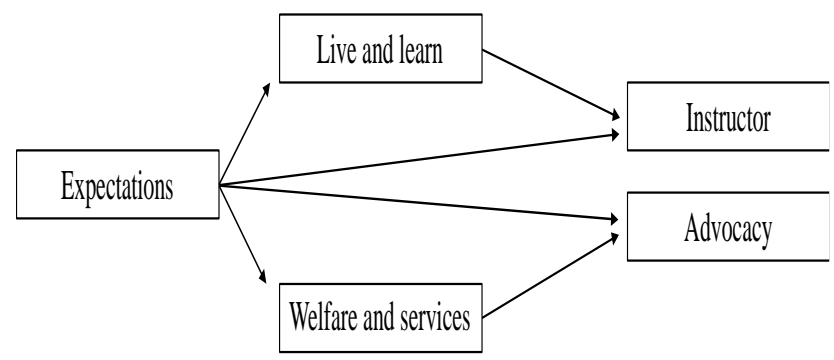

Figure 1 The conceptual framework of the study

\section{Methodology}

The finite population is 554 regular students of the General Management Program (Office of Academic Phranakhon Rajabhat University, 2019).

The sample group is regular students of the General Management Program. The sample size was determined by the Maximum Likelihood method based on the concept of Hair et al., 2010 (Kongmalai and Distanon, 2018), which calculated from 10 - 20 times of 34 observed variables. Therefore, the appropriate number of samples was 340, which was sampled by probability sampling utilizing a simple random sampling method. In this study, 403 samples were collected and screened, which was 11.85 times of observed variables.

The instrument used for data collection was an online questionnaire, which consisted of close-ended questions. It is a 7-level estimation scale based on Wongrattana's concept (2017). The questionnaire was divided into 5 groups of factors, including 8 items of expectation (E; E1 - E8), 11 items of live and learn (L; L1 - L11), 8 items of welfare and services (W; W1 - W8), 4 items of instructor (I; I1 - I4), and 3 items of advocacy (A; A1 - A3). The questionnaire was developed from concepts, theories, and related research from assorted scholars.

The quality checks of the instrument are as follows: (1) Examination of content validity by considering contents, significances, and languages from a total of three senior experts. It was found that the index of Item-Objective Congruence (IOC) of the total 34 questions was in a range between $0.67-1.00$, which was more than 0.50 . This was considered as a practical validity value (Wongrattana, 2017). The researchers then tried out the questionnaire on a sample of 30 people, before testing in the next step. (2) Analysis of the total discriminant power of the questions was in between $0.692-0.908$. The value of more than 0.20 with statistical significance at 0.05 , confirmed high discrimination and quality of the questionnaire (Wongrattana, 2017). (3) The reliability was analyzed using Cronbach's alpha coefficient ( $\alpha$-coefficient). The calculated $\alpha$-coefficient of the whole questionnaire was 0.986 , and the value for individual questions was between $0.985-0.986$. The $\alpha$-coefficient over 0.70 thus proved high reliability of the instrument (Kongmalai and Distanon, 2018). (4) The structural validity was investigated by the statistical method of confirmatory factor analysis. It appeared that a total of 5 factors in this study was structurally consistent.

The data were collected as follows: (1) The researchers prepared an online questionnaire employing Google Form Application (Butchiwan and Lekchareon, 2019; Sukchareon, 2018) by using screening questions (to screen and distribute the sample for each grade). The system would automatically screen and instantly end the questionnaire if the samples answer other questions which are not relevant to the condition. (2) A total of 450 responses, in which 403 responses $(89.56 \%)$ were the samples, was collected. This large number was adequate to be practically used as good representatives of the population in the appropriate criteria. Analyses of the collected data from 403 samples were performed as follows: (1) Analysis of the total discriminant power of the questions ranged in between $0.642-0.835$. The value of more than 0.20 with a statistical significance level at 0.05 assured high discrimination and quality of the questionnaire (Wongrattana, 2017). (2) Analysis of reliability was constructed using Cronbach's alpha coefficient ( $\alpha$-coefficient). It was found that $\alpha$-coefficient of the whole questionnaire 0.981, while it was in between $0.980-0.981$ for individual questions. This confirmed the excellent reliability of the tool in this study. (3) The normal distribution of the observed variables for each factor was examined by analyses of skewness and kurtosis. It was found that the skewness and kurtosis values were between 0.187 and 0.734 , and -0.033 and 0.205 , respectively. The values in the range of $+/-1.96$ with the significance level at 0.05 showed that the collected data from a total of 34 observed variables had a characteristic of the normal distribution (Sukchareon, 2018). (4) The structural validity was tested by the statistical method of confirmatory factor analysis. It was found that various indices aligned within appropriate criteria, confirming structural concordance (Angsuchoti, 2014; Kaiyawan, 2013).

Statistics used in data analyses consisted of descriptive statistics (percentage, mean, skewness, and kurtosis), and 
inferential statistics (Pearson's correlation coefficient, confirmatory factor analysis for structural validity, and path analysis). This is to find the causal relationship model with Structural Equation Modeling (SEM) using software for social science. In data analysis by inferential statistics, the researchers defined the presentation of analytical result into two procedures as follows: (1) The establishment of the causal relationship model of advocacy of the Business Administration Program in General Management. (2) The examination of concordance between the causal relationship model of advocacy of the Business Administration Program in General Management and the empirical data.

\section{Result Summary}

1. The results of building The Causal Relationship Model of Advocacy of the Business Administration in General Management showed that influenced factors for being advocacy consisted of 5 independent variables. They were categorized into 2 types of unobserved variables, which are exogenous and endogenous. The exogenous variable was the expectation. The endogenous variables are live and learn, welfare and services, instructor, and advocacy. The researchers developed and drafted the model based on relevant concepts, theories, and research in order to illustrate various symbols and abbreviations used in the research. They are represented as follows:

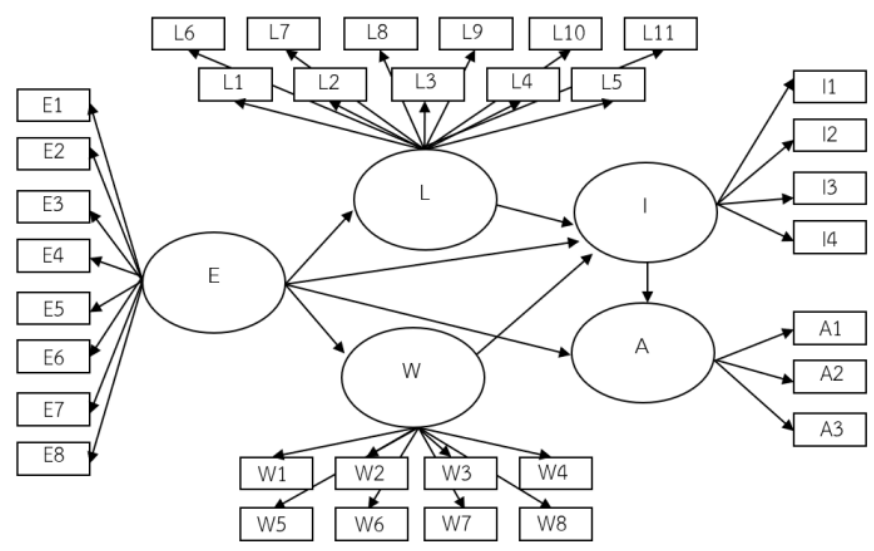

Figure 2 The hypothetical model of advocacy of the business administration program

2. The results of the examination of the concordance between the causal relationship model of advocacy in the Business Administration Program in General Management and the empirical data

2.1 The comparison of the concordance of the causal relationship model before and after adjusting as shown in

Table 1. The concordance indices of the causal relationship model of advocacy of the Business Administration Program in General Management and the empirical data (Angsuchoti, 2014; Kaiyawan, 2013)

\begin{tabular}{|c|c|c|c|}
\hline \multirow{2}{*}{ Index } & \multirow{2}{*}{ Criteria } & $\begin{array}{c}\text { The } \\
\text { unadjusted } \\
\text { model }\end{array}$ & $\begin{array}{c}\text { The adjusted } \\
\text { model }\end{array}$ \\
\hline & & $\begin{array}{lc}\text { Resu } & \text { Analy } \\
\text { lting } & \text { tical }\end{array}$ & $\begin{array}{ll}\text { Resu } & \text { Anal } \\
\text { lting } & \text { ytical }\end{array}$ \\
\hline
\end{tabular}

\begin{tabular}{|c|c|c|c|c|c|}
\hline & & $\begin{array}{c}\text { valu } \\
\text { e }\end{array}$ & result & $\begin{array}{c}\text { valu } \\
\text { e }\end{array}$ & $\begin{array}{c}\text { resul } \\
\mathbf{t}\end{array}$ \\
\hline $\begin{array}{l}\text { Chi-square } \\
\text { (P-value) } \\
\text { Degree of } \\
\text { freedom (df) }\end{array}$ & $\begin{array}{c}\text { No } \\
\text { statistical } \\
\text { significan } \\
\text { ce } \\
(\mathrm{P}>0.05)\end{array}$ & $\begin{array}{c}1,72 \\
0.27 \\
(\mathrm{P}=0 . \\
00) \\
520\end{array}$ & $\begin{array}{l}\text { Not } \\
\text { pass }\end{array}$ & $\begin{array}{c}455.1 \\
6 \\
(\mathrm{P}=0 . \\
10) \\
418\end{array}$ & Pass \\
\hline CMIN/df & $\begin{array}{c}\leq 2.00 \\
\text { (excellent } \\
\text { ) }\end{array}$ & 3.31 & Failed & 1.09 & $\begin{array}{c}\text { Passe } \\
\text { d }\end{array}$ \\
\hline GFI & $\geq 0.90$ & 0.79 & $\begin{array}{c}\text { Passe } \\
\text { d }\end{array}$ & 0.94 & $\begin{array}{c}\text { Passe } \\
\text { d }\end{array}$ \\
\hline AGFI & $\geq 0.90$ & 0.76 & Failed & 0.91 & $\begin{array}{c}\text { Passe } \\
\text { d }\end{array}$ \\
\hline CFI & $\geq 0.90$ & 0.91 & $\begin{array}{c}\text { Passe } \\
\mathrm{d}\end{array}$ & 0.99 & $\begin{array}{c}\text { Passe } \\
\mathrm{d}\end{array}$ \\
\hline $\begin{array}{l}\text { Hoelter index } \\
(\text { at } \mathrm{P}=0.05)\end{array}$ & $\geq 200$ & 135 & Failed & 413 & $\begin{array}{c}\text { Passe } \\
\text { d }\end{array}$ \\
\hline SRMR & $<0.05$ & 0.05 & Failed & 0.02 & $\begin{array}{c}\text { Passe } \\
\mathrm{d}\end{array}$ \\
\hline RMSEA & $<0.05$ & 0.07 & Failed & 0.04 & $\begin{array}{c}\text { Passe } \\
\text { d }\end{array}$ \\
\hline
\end{tabular}

The results found that; the causal relationship model of the advocacy was consistent with empirical data with 455.16 for chi-square test at 418 degree of freedom and $0.10 \mathrm{p}$-value for the adjusted model. Standardized root mean square residual (SRMR) and root mean square error of approximation (RMSEA) were 0.02 and 0.04 , which aligned with the criterion where SRMR and RMSEA must be less than 0.05. Indices, GFI, AGFI, CFI and Hoelter for p-value 0.05 were $0.94,0.91,0.99$, and 413 , respectively. These indices were in between $0.90-1.00$, assured that the model was appropriate and consistent. Moreover, Hoelter index for p-value 0.05 , which must be greater than 0.05 or equal to 200, suggested the consistency between that the causal relationship model of advocacy of the Business Administration Program in General Management and empirical data (Angsuchoti, 2014; Kaiyawan, 2013). The statistical result from the model consistent with empirical data is shown in Figure 3. 


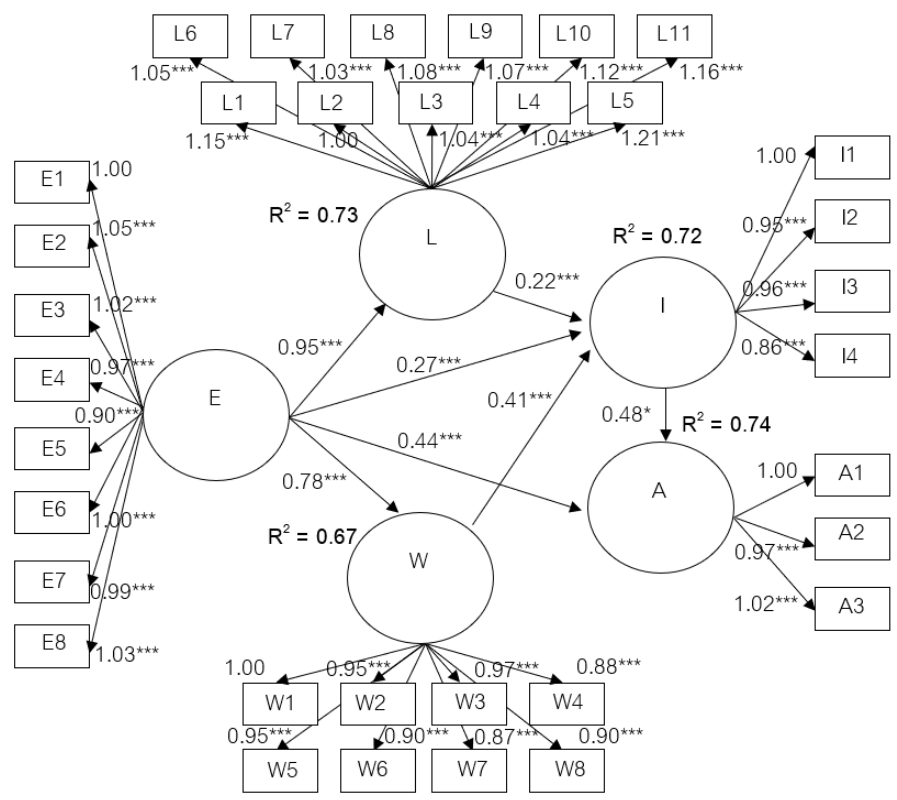

Figure 3 Statistical result of the causal relationship model of advocacy of the Business Administration Program in General Management consistent with empirical data

2.2 From the results above, the researchers analyzed direct effect, indirect effect, and total effect among unobserved variables of the model, which significantly influenced being advocacy of the Business Administration Program. The results were summarized in descending order as depicted in Table 2.

Table 2. Values of direct effect, indirect effect, and total effect among unobserved variable

\begin{tabular}{|c|c|c|c|c|c|c|c|c|c|c|c|c|}
\hline 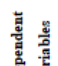 & & E & & & L & & & $\mathbf{w}$ & & & I & \\
\hline 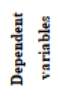 & TE & IE & $\mathrm{DE}$ & TE & IE & $\mathrm{DE}$ & $\mathrm{TE}$ & IE & $\mathrm{DE}$ & TE & $\begin{array}{l}\text { I } \\
\text { E }\end{array}$ & $\mathrm{DE}$ \\
\hline L & $\begin{array}{l}0.95 \\
* * * *\end{array}$ & & $\begin{array}{l}0.95 \\
* * *\end{array}$ & - & - & - & - & - & - & - & - & - \\
\hline w & $\begin{array}{l}0.78 \\
* * *\end{array}$ & & $\begin{array}{l}0.78 \\
* * *\end{array}$ & - & - & - & - & - & - & - & - & - \\
\hline I & 0.83 & 0.56 & $\begin{array}{l}0.27 \\
* * *\end{array}$ & $\begin{array}{l}0.22 \\
* * *\end{array}$ & - & $\begin{array}{l}0.22 \\
* * *\end{array}$ & $\begin{array}{l}0.41 \\
* * *\end{array}$ & - & $\begin{array}{l}0.41 \\
* * *\end{array}$ & & - & - \\
\hline A & 0.83 & 0.39 & $\begin{array}{c}0.44 \\
\text { *** }\end{array}$ & 0.11 & 0.11 & - & 0.20 & 0.20 & - & $0.48^{*}$ & - & $0.48^{*}$ \\
\hline
\end{tabular}

$\mathrm{TE}=$ total effect, $\overline{\mathrm{IE}}=$ Indirect effect, $\mathrm{DE}=$ direct effect, $* \mathrm{p}$ $<0.05$ or $* * * \mathrm{p}<0.001$

From Table 2, direct effects for advocacy (A) in descending order were instructor I, (0.48) and expectation, E (0.44), for p-value 0.05 and 0.01 , respectively. Whereas, indirect effects for advocacy (A) were expectation, E (0.39), welfare and services, W (0.20), and live and learn, L (0.11). Finally, the total effects for advocacy (A) in descending order were expectation, E (0.83), instructor, I (0.48), for p-value 0.05 . While, welfare and services (W), and live and learn (L), which were 0.20 and 0.11 , could be used to explain the variance of advocacy (A) by $74 \%$.

\section{Discussion}

The causal relationship model of advocacy of the Business Administration in General Management was consistent with empirical data. Each factor affected the advocacy of the Business Administration Program as follows:

1. Instructor - This factor is a direct effect on advocacy. It is concordant with the study of Thipboonsub and Rojsonkram (2018), which found that the relationship with the instructor was similar to the relationship with Mahidol University International College. It is also in line with the research from Panawiwat, Adulkittipisai, Wiriyasakulthon and Jutorapat (2017), that students at Mahidol University need intellectual instructors in order to effectively gain knowledge and experience from the experts. This is consistent with the concept of creating of employees to be contact points from Wichitchamaree (2016) to provide customers with valuable experiences as promised from the brand. Employees can also be brand's representatives to build positive experiences as delivered from the brand, and create a good impression for customers throughout sales services, including before, during, and after. This is to initiate a favourable attitude towards the brand in the longterm.

2. Expectation - This is a direct effect, indirect effect, as well as total effect on advocacy. This is consistent with the research from Panawiwat, Adulkittipisai, Wiriyasakulthon and Jutorapat (2017), which found that students expect that their knowledge can be applicable for working development after graduation. They also expect that the programs would be widely accepted by external agencies. Besides, the contents in the course would be applicable, and up-to-date with a substantial plan which would allow them to complete it in a specified period. Moreover, the program with a suitable number of credits and courses would spontaneously encourage students to learn and develop with full potential as well. The obtained results also align with the concept of Office of the Higher Education Commission (2018). It states that higher education institutions nowadays need to adapt and build trust in students that they would obtain high quality, delightful, applicable, convenient, and safe education. This is to create different learning foundations for appropriate opportunities as time and context changes.

3. Live and learn - It is considered as an indirect effect and total effect on advocacy. It had consistency with the study from Teerateep (2018), finding that activities help students to be successful in learning and personal development. The preparation for new students in learning skill and adaptation in education, friends, and living, would increase enjoyment for their studies, as higher education differs from secondary school. Live and learn is also coherent with the results from Thipboonsub and Rojsongkram (2018). They found that bonding among students (seniors, juniors, and friends) by participating in college events and student club activities, was similar to the relationship to Mahidol University International College. It is also consistent with the concept of Samittikrai (2018) that customers would have a satisfying impression as they are helped and resolved with any issue. Therefore, there is a possibility of continuous customers' support or repurchasing 
after receiving services or using products. It is likely to gain brand loyalty from customers when repurchasing repeatedly occur for several times. This could eventually become an emotional commitment from customers to the brand.

4. Welfare and services - are indirect effect and total effect in which consistent with the research by Thangwongsa, Srinonyang, Apaiso, Chotichai and Sariya (2018). It suggests that factors involving objects, environment, as well as services in building sites for students, affected the quality of their living in Mahamakut Buddhist University. It is also in concordance with the study from Krainatee, Muhamad and Nakudon (2017) which found that a provision of welfare for students (housing services, activities for essential life skills, promoting careers, scholarships, services for food and facilities, healthcare services, security, and recreation activities) would create proper immunity for students according to the concept of social welfare. Moreover, this factor aligned with the concept of Office of the Higher Education Commission (2018). It dictates that student welfare and services system organized by higher education institutions should provide supports in scholarships (both in student loans and poverty scholarships), extra-curricular activities, volunteer works, accommodations, cafeterias, shuttle bus services, etc. which would enable students to learn, adapt, and have selfresponsibility.

5. Advocacy - is in line with the study by Peungposop, Junprasert, Yoelao and Kaewmano (2016) which found that the level of perception in internal branding and emotional commitment of employees indicating the level of commitment of employees to the brand. This would create a good relationship between staffs and the brand, as well as develop a better bond too. This factor is also consistent with the research of Thongdang (2018) which said that advocacy of the brand from employees was reflected in employee behaviours, which expressed in performance and delivery of value and the brand commitment to customers or third parties. In line with the concept of Isaraphakdee (2018), which states that when customers have good satisfactions, well brand's perceptions, and inspirations created by the brand, they would willingly convey or share their experiences with the brand to others. Moreover, they would support the brand, as if they are brand's representatives with understanding and willingness. This would allow the formation of a good relationship between brands, customers, as well as internal stakeholders as well. Concurring with the idea of Sriyothin (2017), attitudes of employees to the brand continually influence their behaviours on delivery the brand commitment to customers.

\section{Suggestions}

From the results above, they empirically suggest the findings in this research could be used to apply in being advocacy of the business administration program in general management, by focusing on the followings:

1. Promote and develop the instructors; to be a good role model with teaching ethics (I3), to be able to advise students on rules and policies of the university (I2), to be knowledgeable in teaching and transferring expertise appropriately (I4), and to take care of students by counselling and helping them through obstacles (I1), respectively.

2. Develop the curriculum to meet the expectations and build trust in students; to enable them to pursue careers in business administration according to their aptitudes and interests (G2), to be self-employed by creating digital businesses, online businesses, E-commerce businesses, and social media businesses (G8), to be recognized by society, family, colleagues, and friends (G6), to be able to work in private organizations (G7), to be able to continue in higher education (G4), To have skills in modern business management and digital business (G5), and to be able to work as a government official (G1), respectively.

3. Support and encourage collaboration with faculties and universities for promoting welfare and services; in good and convenient health services (W3), locations and facilities for activities, recreations, and clubs (W2), locations and equipment for exercises and sports (W5), scholarships and funding sources for students (W8), secure dormitories (W6), modern libraries and information systems (W4), cafeterias and stores (W7), and a proper environment for learning and relaxation (W1), respectively. 4. Promote and support cooperation with faculties and universities to enhance live and learn experiences in university; by providing staffs assisting in helping and communicating with universities for any activities (L5), preparation for the development of abilities and skills in digital technology (L11), senior students for taking care and advising in learning, activity and living in university (L1), arrangement for the development in communication skills, interpersonal relationships, and responsibilities (L10), suitable plans for learning and activities for student enhancement, which is consistent with lifestyles, in both personal and collaborative of students (L8), student team building for academic activity development (L9), preparation for the development in numerical analysis and calculation (L6), collaboration among students in participating in beneficial activities for the 4-year program (L3), preparation for advancement in morals, ethics, and other skills (L4), the arrangement in enhancing language skills (L7), as well as classmates which would create supportive and helpful atmosphere for learning throughout the program (L2), respectively.

Be the program advocacy; to make students willingly sharing stories and experiences of their learnings to others (A3), to support and encourage the learners to contribute their impressions and prides arisen in their field of study (A2), and to allow students to create happiness and experiences together for learning and self-development (A1), respectively.

\section{References}

[1] Angsuchoti, S. (2014). Statistics for Social Science and Behavior Research: Technical Support for Users of Lisrel. 4th ed. Bangkok: Charoendee Munkong Press. (in Thai) 
[2] Butchiwan, P. \& Lekchareon, S. (2019). The Causal Relationship Model of Brand Love via Online Social Media of Consumers in Bangkok and Vicinity. Journal of Southern Technology. 12(1), 72-83. (in Thai)

[3] Isaraphakdee, P. (2018). Branding 4.0. 9th ed. Bangkok: Amarin How to Press. (in Thai)

[4] Kaiyawan, Y. (2014). Analysis for Structural Model Equation with AMOS. Bangkok: Chulalongkorn Press. (in Thai) in, A. \& Distanon, A. (2018). Research Techniques in Technology and Innovation Management. Bangkok: Thamasart University Press. (in Thai)

[6] Krainatee, M., Muhamad, C. \& Nakudom, S. (2017). Ways of Providing Appropriate Welfare for Students of Nakhon Si Thammarat Rajabhat University. Narkbhut Paritat Journal. 9(2), 97-107.

[7] Office of Academic Phranakhon Rajabhat University, (2019). Student Report 2019. Retrieved January 31, 2020, from

http://etcserv.pnru.ac.th/Offi/acade/statistic -jeab/62/month/11/2.pdf

[8] Office of the Higher Education Commission, (2018). Ways of Providing Welfare and Services for Students of Higher Education. Retrieved January 31, 2020, from http://www.stud.mcu.ac.th/?p=1490

Panawiwat, W., Adulkittipisal, L., Wiriyasakulthon, J. \& Juturapat, S. (2017). Needs and expectations of students for the Graduate School, Mahidol University. Integrated Social Science Journal, Faculty of Social Sciences and Humanities, Mahidol University. 4(2), 51-82. (in Thai)

[10] Peungposop, N., Junprasert, T., Yoelao, D. \& Kaewmano, C. (2016). Brand Image, Internal Branding, and Affective Brand Commitment of Staff in Thai University. Journal of Behavioral
Science for Development. 8(2), 71-91. (in Thai)

[11] Wongrattana, S. (2017). Technical for Research Instrument. Bangkok: Armorn Press. (in Thai)

[12] Rimpadee, W., Mookda, W., Prapakiet, T. \& Supakitkosol, P. (2015). Factors in Decision Making of undergraguate Students in Further Study at Suan Dusit University. Journal of Education Review Faculty of Education in MCU. 2(3), 38-55. (in Thai)

[13] Samittikrai, C. (2018). Consumer's Behavior. 8th ed. Bangkok: Chulalongkorn Press. (in Thai)

[14] Sriyothin, S. (2017). Internal Communication from Internal Branding Concept . Veridian E-Journal, Silpakorn University Humanities, Social Sciences and Arts. 10(2), 1025-1039. (in Thai)

[15] Sukcharoen, W. (2018). Marketing Research. Bangkok: Chulalongkorn Press. (in Thai)

[16] Teerateep, A.(2018). Factors Affecting of Students' Happiness Learning in Burapha University. Master of Education Program in Education Administration, Faculty of Education, Burapha University. (in Thai)

[17] Thanwongsa, K., Srinonyang, P., Apaiso, P., Chotichai, B. \& Sariya, W. (2018). Factors Influencing Quality of Student Life in Mahamakut Buddhist University, Srilanchang Campus. MBU Education Journal: Faculty of Education Mahamakut Buddhist University. 6(1), 545-565. (in Thai)

[18] Thipboonsub, J. \& Rojsongkram, S. (2018). An Exploratory of Student Engagement between Undergraduates and Mahidol University International College. Mahidol R2R e-Journal. 4(1), 56-69. (in Thai)

[19] Thongdaeng, H., et.al. (2018). Internal Branding and Communication on Brand Supporting Behaviours of Employees of Private Organization Invading Asean. Journal of Suwanapoom 
Institute of Technology (Humanities and Social Sciences). 4(1), 274-290. (in Thai)

[20] Wichitchamaree, N. (2016). Principles of Public Relations. Bangkok: Kasetsart University Press. (in Thai) 